\title{
A Novel Focal Seizure Pattern Generated in Superficial Layers of the Olfactory Cortex
}

\author{
Laura Uva, ${ }^{1}$ Stefania Saccucci, ${ }^{2}$ Maia Chikhladze, ${ }^{3}$ Laura Tassi, ${ }^{4}$ Vadym Gnatkovsky, ${ }^{1}{ }^{\circledR}$ Gloria Milesi, ${ }^{1}$ Michela Morbin, ${ }^{2}$ \\ and Marco de Curtis ${ }^{1}$ \\ ${ }^{1}$ Unit of Epileptology, ${ }^{2}$ Unit of Neuropathology, and ${ }^{3}$ Unit of Clinical Neurophysiology, Fondazione Istituto Neurologico Carlo Besta, 20133 Milano, Italy, \\ and ${ }^{4}$ Claudio Munari Epilepsy Surgery Center, Ospedale Niguarda Ca' Granda, 20162 Milano, Italy
}

Seizure patterns identified in focal epilepsies caused by diverse etiologies are likely due to different pathogenic mechanisms. We describe here a novel, region-specific focal seizure pattern that mimics seizure activity observed in a subpopulation of patients submitted to presurgical monitoring with intracerebral electrodes. Distinctive seizure-like events (SLEs) are induced in the olfactory regions by acute treatment of both tangential brain slices and the isolated guinea pig brain with the potassium channel blocker 4-aminopyridine. Analysis of field potentials, intracellular activities, and extracellular potassium changes demonstrates that SLEs in the piriform cortex initiate in the superficial layer 1 lacking principal neurons with an activity-dependent increase of extracellular potassium. SLE progression (but not onset) does not require the participation of synaptic transmission and is mediated by diffusion of potassium to deep cortical layers. The novel seizure pattern here described is not observed in other cortical regions; it is proposed to rely on the peculiar organization of the superficial piriform cortex layers, which are characterized by unmyelinated axons and perisynaptic astroglial envelopes. This study reveals a sequence of ictogenic events in the olfactory cortex that were never described before in other cortical structures and supports the notion that altered potassium homeostasis and unmyelinated fibers may represent a potential vehicle for focal ictogenesis.

Key words: 4-aminopyridine; extracellular potassium; human intracerebral EEG recordings; in vitro guinea pig brain

\section{Significance Statement}

We describe a novel seizure pattern peculiar of the olfactory cortex that resembles focal seizures with low-voltage fast activity at onset observed in humans. The findings suggest that network mechanisms responsible for seizure onset can be region specific.

\section{Introduction}

Different seizure patterns have been identified by direct intracerebral recordings in patients with focal pharmacoresistant epilepsies submitted to presurgical EEG monitoring with depth electrodes (Perucca et al., 2014; Singh et al., 2015). Because focal epilepsies are caused by a variety of etiologies that affect neurons and/or glia, it is likely that different mechanisms are responsible for ictogenesis: the early events that initiate a seizure. Seizure

Received July 14, 2016; revised Dec. 6, 2016; accepted Dec. 16, 2016.

Author contributions: L.U., M.M., and M.d.C. designed research; L.U., S.S., M.C., L.T., V.G., and G.M. performed research; L.U., S.S., M.C., L.T., V.G., and G.M. analyzed data; L.U. and M.d.C. wrote the paper.

This work was supported by the Telethon Foundation (Grant GGP12265), the Fondazione Banca del Monte di Lombardia, 2015-2017, and the Italian Health Ministry (Finanziamento di Ricerca Corrente, 2012-2015; Progetto Finalizzato Giovani Ricercatori, 2011-02348633). We thank Rita Garbelli for suggestions on myelin staining of PC slices, Barbara Cipelletti for the technical assistance, and Federica Trombin for contributing to the experiments.

The authors declare no competing financial interests.

Correspondence should be addressed to Marco de Curtis, Unit of Epileptology and Experimental Neurophysiology, Fondazione Istituto Neurologico Carlo Besta, Via Celoria 11, 20133 Milano, Italy. E-mail: marco.decurtis@istituto-besta.it.

DOI:10.1523/JNEUROSCI.2239-16.2016

Copyright $\odot 2017$ the authors $\quad 0270-6474 / 17 / 373544-11 \$ 15.00 / 0$ discharges identified in humans (Bragin et al., 1999b; Lee et al., 2000; Tassi et al., 2002; Ogren et al., 2009) can be reproduced in animal models to examine with experimental techniques the cellular and tissue factors that contribute to their generation (de Curtis and Gnatkovsky, 2009). This approach represents a rational and realistic strategy to understand seizures and ictogenesis. It has been demonstrated that acute pharmacological manipulations with various proepileptic drugs in the isolated guinea pig brain maintained in vitro by arterial perfusion generate interictal and ictal epileptiform patterns that are region specific and depend on the network organization of the involved cortical area (de Curtis et al., 1994; Librizzi and de Curtis, 2003; Uva et al., 2005; Carriero et al., 2010; de Curtis et al., 2016). In this closeto-in vivo preparation, the arterial perfusion of the potassium channel blocker 4-aminopyridine (4AP) causes two distinct and independent seizure-like events (SLEs) in the limbic and olfactory regions (Carriero et al., 2010). SLEs in the olfactory areas show a peculiar pattern different from that observed in temporal lobe cortices; these SLEs originate in the piriform cortex (PC; Carriero et al., 2010; Uva et al., 2013), a three-layer cortex 
that receives the largest inputs from olfactory bulbs (Neville and Haberly, 2004).

Experimental studies performed in vivo (Piredda and Gale, 1985; Löscher and Ebert, 1996) and in vitro (Galvan et al., 1982; Hoffman and Haberly, 1993, 1996; de Curtis et al., 1994; Federico and MacVicar, 1996; Demir et al., 1999, 2001; Carriero et al., 2010; Panuccio et al., 2012; Uva et al., 2013) demonstrated that the PC has a low epileptogenic threshold. Moreover, in human focal epilepsies arising from different cortical locations, the piriform area has been identified as a prominent and common source area of active interictal EEG spiking (Laufs et al., 2011; Centeno et al., 2014).

It has been demonstrated previously that 4AP-induced SLEs recorded in PC emerge from runs of fast activity in the beta/ gamma range $(20-60 \mathrm{~Hz})$ and progress with the recruitment of synchronous spiking discharges (Uva et al., 2013). The analysis of neuronal activity demonstrated that cells in the superficial layer 2 are not particularly active at SLE onset. Deep layer cells undergo sparse firing and show no bursting activity throughout the ictal event. The mechanisms underlying the onset of this peculiar SLE pattern are still to be determined and are analyzed here. We used the isolated guinea pig brain and in vitro slices to define the ictogenic trigger of 4AP-induced SLE in the PC. We also report that seizures with similar electrographic features and evolution patterns have been identified with intracranial stereo-EEG in a cohort of patients suffering from drug-resistant focal epilepsy.

\section{Materials and Methods}

\section{Experimental preparations}

Isolated guinea pig brain maintained in vitro. Adult Hartley female guinea pigs (150-200 g; Charles River Laboratories) were used for the experiments. Animals were deeply anesthetized by intraperitoneal injection of sodium thiopental $(125 \mathrm{mg} / \mathrm{kg}$, Farmotal; Pharmacia). The heart was exposed and intracardiac perfusion was performed with a cold $\left(4^{\circ} \mathrm{C}\right)$, carboxygenated $\left(95 \% \mathrm{O}_{2} / 5 \% \mathrm{CO}_{2}\right)$ solution containing the following (in mM): $126 \mathrm{NaCl}, 3 \mathrm{KCl}, 1.2 \mathrm{KH}_{2} \mathrm{PO}_{4}, 1.3 \mathrm{MgSO}_{4}, 2.4 \mathrm{CaCl}_{2}, 26 \mathrm{NaHCO}_{3}$, 15 glucose, and 2.1 HEPES plus $3 \%$ dextran (MW 70,000), $\mathrm{pH}$ 7.2. After 3 min of perfusion, the animal was decapitated and the brain was carefully dissected out (for details, see de Curtis et al., 1991, 1998; Mühlethaler et al., 1993) and placed in the recording chamber. A polyethylene cannula was inserted in the basilar artery to restore the perfusion with the same saline solution, $\mathrm{pH}$ 7.4. The temperature of the chamber was raised from $15^{\circ} \mathrm{C}$ to $32^{\circ} \mathrm{C}$ by steps of $0.2^{\circ} \mathrm{C} / \mathrm{min}$.

Guinea pig PC slices. Hartley guinea pigs were deeply anesthetized with isoflurane (Aerrane, $4 \%$; Baxter) and decapitated. Brains were removed and placed in ice-cold ACSF containing the following (in mM): $126 \mathrm{NaCl}$, $3.5 \mathrm{KCl}, 2 \mathrm{CaCl}_{2}, 2 \mathrm{MgSO}_{4}, 1.2 \mathrm{NaH}_{2} \mathrm{PO}_{4}, 26 \mathrm{NaHCO}_{3}$, and 10 glucose, pH 7.3-7.4, bubbled with $95 \% \mathrm{O}_{2} / 5 \% \mathrm{CO}_{2}$. Slices, $500 \mu$ m thick, were cut in the coronal plane or in a plane tangential to the PC surface using a vibratome. Slices were transferred to an interface chamber and perfused with ACSF at $35^{\circ} \mathrm{C}$.

To induce epileptiform activity, the spurious potassium channel blocker 4AP (50 $\mu \mathrm{M}$; Tocris Bioscience) was either arterially perfused for $4 \mathrm{~min}$ in the isolated whole brain or bath applied to PC slices; if basal conditions recovered after washout $(>1 \mathrm{~h})$ a second perfusion of $4 \mathrm{AP}$ was performed. The non-NMDA glutamate receptors blocker 6,7dinitroquinoxaline-2,3-dione (DNQX; $50 \mu \mathrm{m}$; Sigma-Aldrich) was dissolved in the perfusate and applied via the resident arterial system.

The experimental procedures were conducted in accordance with ethically approved institutional guidelines in compliance with National and European laws and animal care policies (EEC Council Directive 86/609, OJ L 358, 1, Dec. 12, 1987).

\section{Electrophysiological recordings}

Field potential recordings from the in vitro isolated brains were performed in the PC either with glass capillaries filled with $\mathrm{NaCl} 0.9 \%$ (5-10
$\mathrm{M} \Omega$ resistance) or with linear 16-channel silicon probes (intersite distance of $50 \mu \mathrm{m}$ ). Responses evoked by stimulation of the lateral olfactory tract (LOT) with a custom-made double-wire electrode connected to an isolation unit driven by a pulse generator (Telefactor S88; Grass Instruments) were monitored during the experiment. Electrophysiological signals were acquired at $3 \mathrm{KHz}$ sampling rate with a Biomedical Engineering differential amplifier in DC mode and digitized by a National Instruments A/D board (AT-MIO-64E3).

For intracellular recordings from PC principal cells, sharp electrodes filled with potassium acetate $2 \mathrm{~m}$ and biocytine $2 \%$ (input resistance $60-120 \mathrm{M} \Omega$ ) were used. Signals recorded from pyramidal neurons of PC layers 2 and 3 were acquired with a Neuro Data Instruments amplifier and digitized as detailed above. At the end of the experiments, cells were filled with biocytine pulsed through the recording electrodes. Brains were then fixed in $4 \%$ paraformaldehyde and sectioned in $75-\mu \mathrm{m}$-thick slices by a vibratome. Biocytine was immunoreacted with an avidine-HRP complex (ABC kit; Vector Laboratories) and sections were counterstained with thionine to identify the cell position in PC layers.

To evaluate $\left[\mathrm{K}^{+}\right]_{0}$, double-barrel ion-sensitive electrodes were prepared. One capillary was exposed to dichlorodimethylsilane fumes (Fluka) and heated for $1.5 \mathrm{~h}$ at $120^{\circ} \mathrm{C}$ to fill the tip of the electrode with a resin sensitive to $\mathrm{K}^{+}$(Potassium Ionophore I, Cocktail A; Fluka). The two barrels of the electrodes were then backfilled with either $\mathrm{KCl} 0.2 \mathrm{M}$ (ion-sensitive electrode) or $0.9 \% \mathrm{NaCl}$ (reference barrel). The signals recorded from the reference and the ion sensitive electrodes were fed to a low-impedance differential amplifier (Biomedical Engineering). The subtraction of the reference signal from the ion sensitive signal gave the net increase in $\left[\mathrm{K}^{+}\right]_{\mathrm{o}}$. Before the experiment, the electrodes were calibrated using solutions with known concentration of $\mathrm{K}^{+}$. The voltage (in millivolts) measured was converted to $\mathrm{K}^{+}$concentration values using the formula $Y=s \log X$, where $Y$ is the voltage measured, $s$ is the slope of the calibration curve, and $X$ is the $\left[\mathrm{K}^{+}\right]_{\mathrm{o}}$ concentration (for details, see Librizzi et al., 2001). $\left[\mathrm{K}^{+}\right]_{\mathrm{o}}$ levels were simultaneously monitored in two or three depth positions in the PC. Electrophysiological signal acquisition and offline analysis were performed with ELPHO software (www. elpho.it) developed by Vadym Gnatkovsky in our laboratory. To identify the onset of the most rapid $\left[\mathrm{K}^{+}\right]_{\mathrm{o}}$ shift at surface, the first and the second derivative of the $\left[\mathrm{K}^{+}\right]_{\mathrm{o}}$ trace were computed with OriginPro 2016 software (OriginLab). Quantifications of the $\left[\mathrm{K}^{+}\right]_{\mathrm{o}}$ levels and time peaks were computed offline and are reported as box plots.

Field potentials in slices were recorded in superficial PC layers with glass capillaries filled with $\mathrm{NaCl} 0.9 \%$ (5-10 $\mathrm{M} \Omega$ resistance), using a Neuro Data Instruments amplifier. The viability of slices before bath application of $4 \mathrm{AP}(20-50 \mu \mathrm{M})$ was tested by analyzing the responses to stimulation of LOT or PC layer 1 with bipolar stainless steel electrodes.

\section{Morphological analysis}

To study myelin distribution, $75 \mu \mathrm{m}$ coronal sections were stained with Black-Gold II ( $0.3 \%$ dissolved in $0.9 \%$ saline; Histo-Chem) and counterstained with thionine.

For electron microscopy, guinea pig brains were fixed with $4 \%$ paraformaldehyde in $0.05 \mathrm{M}$ phosphate buffer, $\mathrm{pH}$ 7.4. Areas of interest were detected and postfixed in 1\% osmium tetroxide, dehydrated in graded acetone, and embedded in epoxy resin. For the morphological analysis, semithin sections ( $1 \mu \mathrm{m}$ thick) were cut using an ultramicrotome and counterstained with toluidine blue for light microscopy. Representative ultrathin sections $(800 \AA)$ of selected areas were placed on 200 -mesh copper grids; counterstained with lead citrate, samarium, and gadolinium triacetate; and examined under an EM 104 electron microscope (Tecnai G2 Spirit; FEI). Myelinated and unmyelinated fibers were counted by manual methods in four random fields of layers $1 \mathrm{a}$ and $1 \mathrm{~b}$ at a magnification of $4500 \times$ in a tissue area of $250 \mu \mathrm{m}$.

\section{Human recordings}

Intracerebral stereo-EEG was recorded at the Claudio Munari Epilepsy Surgery Center in patients with focal pharmacoresistant epilepsy candidate to epilepsy surgery. Stereo-EEG was performed with intracerebral multicontact electrodes (DIXI Medical) implanted according to the ste- 
A

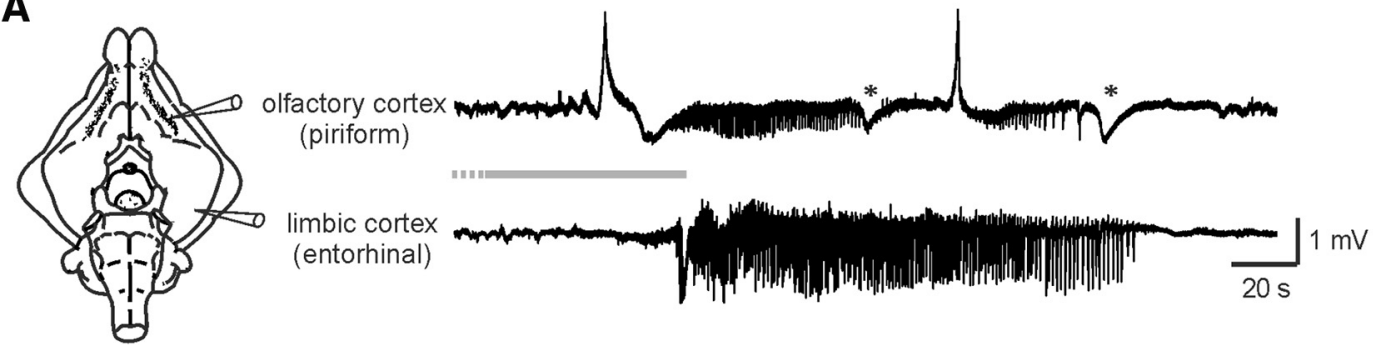

B

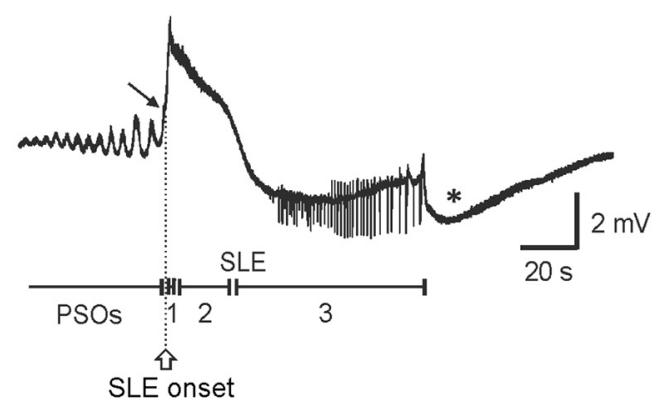

C

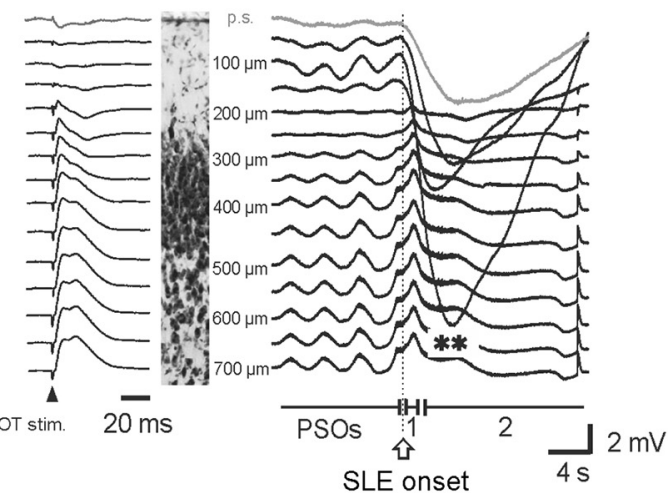

D coronal slice

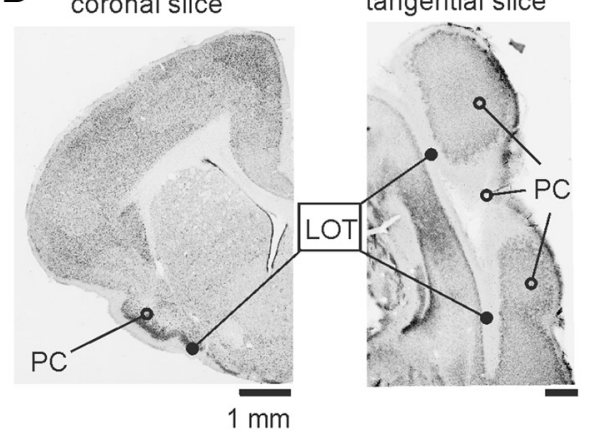

coronal slice

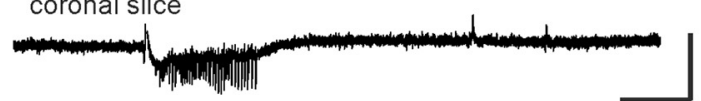

tangential slice

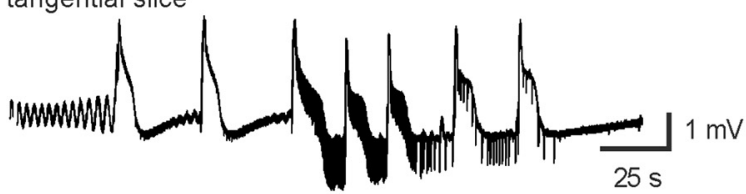

Figure 1. SLE features in the piriform cortex. $A$, Left, Schematic drawing of the isolated guinea pig brain showing the position of the extracellular recording electrodes inserted in the olfactory cortex (piriform) and in the limbic cortex (entorhinal). Right, SLEs induced by arterial perfusion of $4 A P$ ( $50 \mu \mathrm{m} ; 4$ min; gray bar) simultaneously recorded in the piriform (top trace) and entorhinal cortex (bottom trace). Note the different and independent SLE patterns in the two regions. The asterisks mark the slow potential that ends SLEs in PC. B, Example of a SLE transition recorded at 500 $\mu \mathrm{m}$ depth in PC during $50 \mu \mathrm{m}$ 4AP perfusion. PSOs recur before SLE onset. The three SLE phases are indicated, based on the criteria already described (Uva et al., 2013). C, Field potential profile recorded in the $\mathrm{PC}$ with a 16-channel silicon probe (intersite distance: $50 \mu \mathrm{m}$ ). The electrode was inserted perpendicular to $\mathrm{PC}$ lamination. A thionine-stained section of the PC is illustrated. Left, Responses evoked by LOT stimulation (arrow at bottom). Right, Profile recorded during SLE induced by arterial perfusion of 4AP (50 $\mu \mathrm{m}$ ). At seizure onset (open arrow and dotted line), a large negative component (marked by the double asterisk) is observed in the most superficial layer. The trace in gray corresponds to the subpial space external to the $P C$ tissue. $D$, Microphotographs of coronal (left) and tangential (right) PC slices stained with thionine are shown. Right, Representative SLEs recorded from coronal (top) or tangential (bottom) PC slices during bath perfusion with $50 \mu \mathrm{m} 4 \mathrm{AP}$. The activity recorded from the tangential slice resembles SLEs recorded in the whole isolated guinea pig brain.

reotactic method of Talairach et al. (1974) after imaging and electroclinical assessment (Munari et al., 1994; Cossu et al., 2005; Cardinale et al., 2013). Stereo-EEG signals from 13-17 implanted electrodes with a maximum number of 192 recording channels were sampled at $1 \mathrm{kHz}$ with a Neurofax EEG-1100 system (Nihon Kohden). Data were digitized with 16-bit resolution. Informed consent was obtained from all subjects. Seizure patterns were identified with computer-assisted analysis of stereoEEG signal according to previously described methods (Gnatkovsky et al., 2011, 2014).

\section{Statistical analysis}

Statistical analysis was performed with Origin version 8.0 software. Oneway ANOVA coupled with Tukey's post hoc test was used for comparing of multiple groups. The Mann-Whitney nonparametric test was chosen to determine whether two means were statistically different when data were not normally distributed; otherwise, two-sample $t$ test was used. When only the experiments with paired recordings were considered, paired $t$ test and Wilcoxon signed-rank test were chosen. Normal distribution of samples was checked with Shapiro-Wilks test and the homogeneity of variances with Levene's test (always verified with the exception of the data reported in Fig. 4D). The tests are two-sided and significance was set at $p<0.05$ level. Data are expressed as mean \pm SD.

\section{Results}

Simultaneous recordings from the PC and from the medial entorhinal cortex of the in vitro isolated guinea pig brain $(n=40)$ demonstrated that the arterial perfusion of 4AP (50 $\mu \mathrm{M}, 4 \mathrm{~min})$ induces asynchronous interictal and ictal epileptiform activity in olfactory and in limbic regions (Fig. 1A; see also Carriero et al., 2010). SLEs recorded in limbic and olfactory areas during the same 4AP application showed different electrographic features and different time courses, suggesting that 4AP-induced epilep- 
A

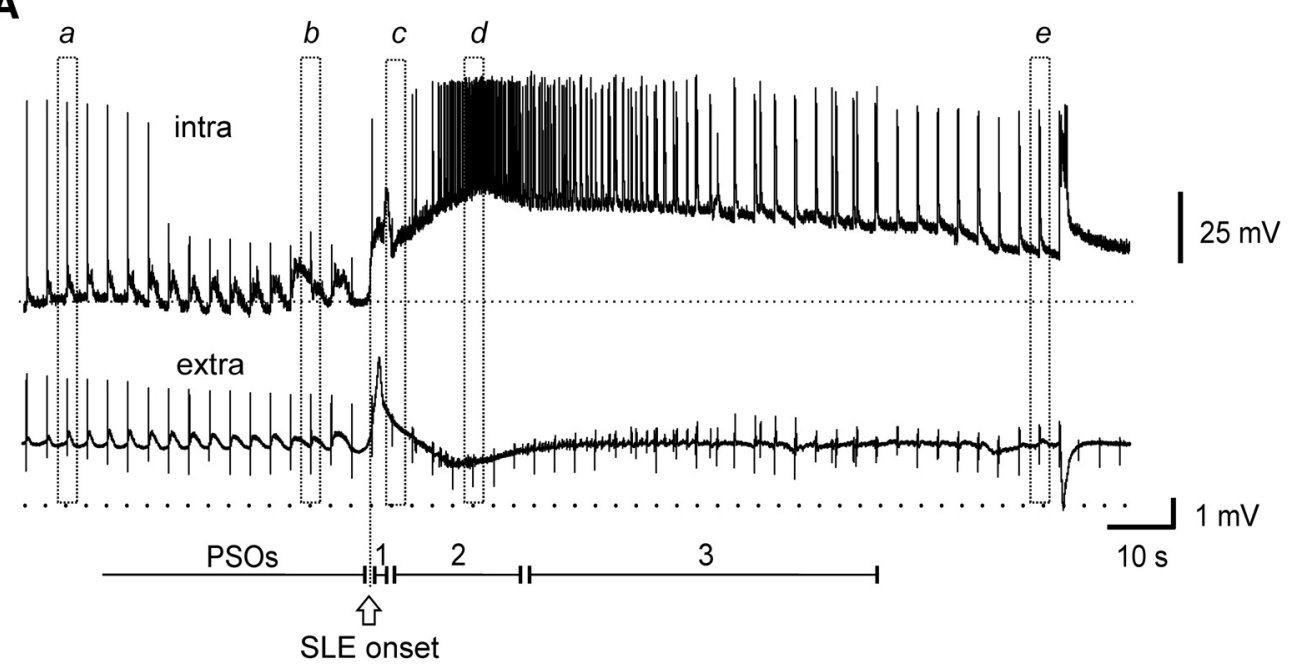

B

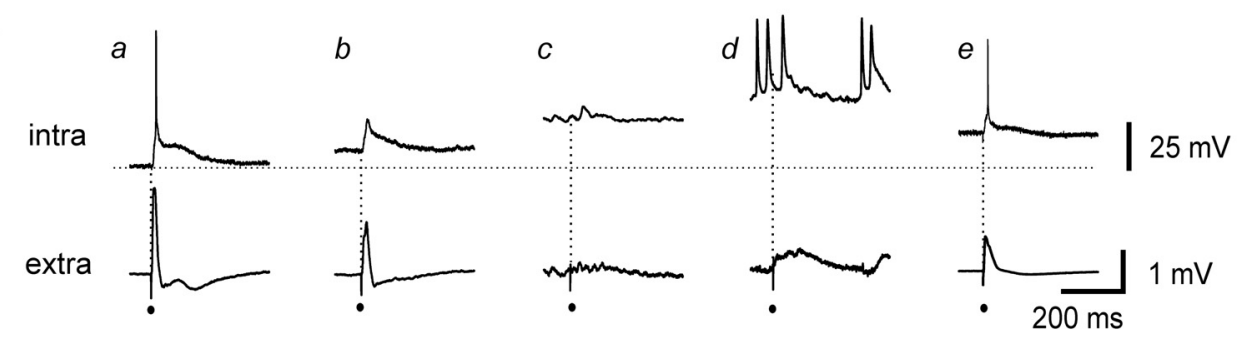

C

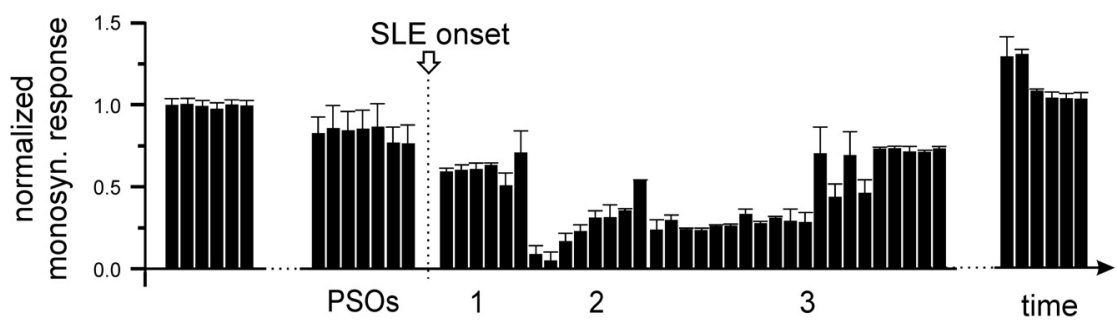

Figure 2. SLE progression correlates with blockade of LOT-evoked synaptic transmission. A, Simultaneous intracellular (intra) and extracellular (extra) recordings of a SLE induced by arterial application of $4 A \mathrm{AP}(50 \mu \mathrm{m} ; 4 \mathrm{~min})$. The intracellular signal was recorded from a layer $3 \mathrm{PC}$ cell at resting membrane potential (dotted line; $-67 \mathrm{mV})$. PSO-SLE phases are indicated at the bottom. During phase 1 and phase 2 , a gradual depolarization of cell membrane and cell firing occur. LOT stimulation was delivered every $3 \mathrm{~s}$ (dots). Sampled responses $a-e$ are reported in $\boldsymbol{B}$ with expanded time scale. Suppression of the action potentials and of LOT-evoked responses in both intracellular and extracellular recordings was observed during SLE. The LOT response recovered after SLE end. C, Amplitude modulation of the LOT-evoked monosynaptic responses (normalized on the maximal pre-4AP amplitude) during SLE progression was quantified and averaged (11 experiments).

tiform discharges depend on the peculiar network arrangement of the specific region (de Curtis et al., 2016). Cellular and network determinants of seizure activity generated in limbic cortices has been described previously (Carriero et al., 2010; Uva et al., 2015). In the present study, we focused on SLEs observed in the olfactory PC.

\section{SLEs in the piriform cortex}

As described previously (Carriero et al., 2010; Uva et al., 2013), 4AP induced in the PC slow sequences of fast activity at $\sim 30 \mathrm{~Hz}$ nested within periodic slow oscillations (PSOs) at $0.1-0.5 \mathrm{~Hz}$ that abruptly switched into seizure discharges. SLEs (mean duration: $58.26 \pm 26.37 \mathrm{~s}$ ) recognized 3 highly reproducible phases (Fig. $1 B$ ): phase 1 correlated with a large amplitude extracellular upward (depth-positive; mean amplitude: $2.54 \pm 1.10 \mathrm{mV}$ at $400 \mu \mathrm{m}$ in depth) potential; phase 2 correlated with fast activity of small amplitude at $30-60 \mathrm{~Hz}$ superimposed to a plateau potential and was followed by phase 3, large-amplitude population spiking (see also Uva et al., 2013). SLEs and the associated spiking terminated abruptly with a large-amplitude, depth-negative, slow deflection (asterisks in Fig. $1 A, B$ ). The network determinants of PC SLE are further detailed in the next paragraphs.

\section{Piriform cortex SLEs originate in layer 1}

In the following experiments, the site of origin of SLEs within the PC was determined. Laminar profile recordings performed with 16-channel linear silicon probes (eight SLEs from eight preparations) demonstrated that SLE onset correlated with a very large surface-negative (depth-positive) potential (double asterisk in Fig. 1C) that showed maximal amplitude at $100 \mu \mathrm{m}$ from the pial surface (corresponding to PC layer 1a; mean amplitude: $22.10 \pm$ $8.94 \mathrm{mV}$; mean duration from the SLE onset: $21.57 \pm 6.11 \mathrm{~s}$ ) and depth reversal at $200 \mu \mathrm{m}(n=8)$. These findings strongly suggested that the slow, large component of SLE phase 1 is generated in the superficial layer of the PC. 


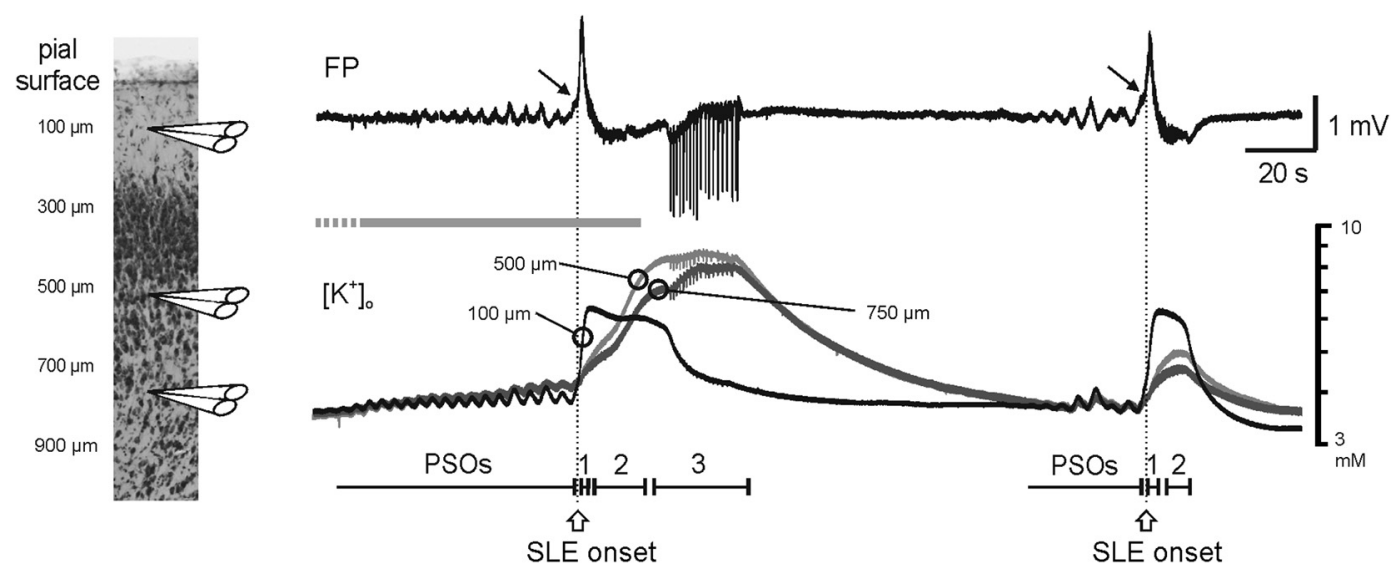

Figure 3. Correlation between SLEs and extracellular potassium concentration $\left(\left[\mathrm{K}^{+}\right]_{0}\right)$. Schematic drawing of the positions of the three $\mathrm{K}^{+}$-sensitive double barrel electrodes is illustrated on the left. The distance from the pial surface of each electrode is indicated on a coronal microphotograph of the PC stained with thionine. Right, Simultaneous field potential recording at $500 \mu \mathrm{m}$ depth (FP) and $\left[\mathrm{K}^{+}\right]_{0}$ shifts recorded at 100,500, and $750 \mu \mathrm{m}$ from the pial surface (black, light gray, and dark gray traces, respectively) during SLEs induced by arterial application of 4AP (50 $\mu \mathrm{m}$; horizontal gray bar). SLE phases are reported in the bottom. The second SLE (right) is shorter and does not present phase 3 . The arrow of FP trace indicates the deflection that marks the initiation of SLEs after PSOS.

In 5 of 6 experiments, PSOs and SLEs were blocked by arterial perfusion of the glutamate receptor blocker DNQX (50 $\mu \mathrm{M} ; n=$ 6 from 6 brains; data not shown), suggesting that local excitatory activity mediated by non-NMDA glutamate receptors is necessary to induce the SLE. The glutamatergic transmission blockade was verified by testing the excitatory response evoked by electrical stimulation of the LOT, which represents the main input to the PC (Neville and Haberly, 2004).

To verify whether superficial PC layers were necessary to the generation of SLEs, we recorded 4AP-induced SLEs in 500- $\mu \mathrm{m}$ thick coronal slices and in slices cut with an angle tangent to the pial PC surface (Fig. 1D). Only the tangential PC slices are expected to maintain an extensive intrinsic organization of superficial PC layers. Extracellular recordings demonstrated that epileptiform activity in 11 of 13 tangential slices (from eight brains) was characterized by repetitive PSOs, followed by SLEs with a large-amplitude upward potential at onset. SLEs in 12 of 15 coronal PC slices (from nine brains) were different from SLEs observed both in the isolated brain and in PC tangential slices (top trace in Fig. 1D; see Discussion). These observations confirmed that the preservation of superficial PC layer networks is essential for the generation of the specific and peculiar SLE pattern observed in the PC of the intact brain.

\section{SLE progression does not require synchronous excitatory synaptic activity}

To evaluate the contribute of synchronous synaptic propagation to the progression and development of SLEs, we monitored the synaptic responses evoked by LOT stimulation during 4AP perfusion. Surprisingly, we observed that intracellular and extracellular responses evoked by LOT stimulation were suppressed during SLEs ( $n=11$ from 11 brains; Fig. 2). LOT-evoked synaptic responses gradually resumed during the late SLE phase and recovered at the end of the SLE (Fig. 2C). As observed previously (Uva et al., 2013), at SLE onset (phase 1), PC neurons depolarized and inconsistently fired; a depolarizing plateau superimposed to action potential firing and occasional bursting activity was recorded during phases 2 and 3 (Fig. 2A). These findings suggest that synchronous synaptic transmission is impaired during SLEs and gradually restores when SLEs come to an end.

\section{SLE is associated with a rapid $\left[\mathrm{K}^{+}\right]_{\mathrm{o}}$ rise in the superficial layer 1}

The evidence reported above suggests that 4-AP-induced synaptic release is necessary for SLE (and PSO) initiation and that conventional synaptic mechanisms are not implicated in SLE progression. To evaluate the role of $\left[\mathrm{K}^{+}\right]_{\mathrm{o}}$ changes, we simultaneously recorded field potentials in isolated 10 brains and $\left[\mathrm{K}^{+}\right]_{\mathrm{o}}$ with 2 ( 9 from 6 brains) or 3 ( 6 from 5 brains) $\mathrm{K}^{+}$-selective electrodes concurrently positioned at 100-150 $\mu \mathrm{m}$ (layer 1), 300 $\mu \mathrm{m}$ (layer 2), and 500/750 $\mu \mathrm{m}$ (layer 2-3) from the pial PC surface $(n=15) \cdot\left[\mathrm{K}^{+}\right]_{\mathrm{o}}$ slowly raised in layer 1 electrode during each PSO (black $\mathrm{K}^{+}$traces in Figs. 3, 4A) and boosted at the transition into SLE. The delay of the maximal $\left[\mathrm{K}^{+}\right]_{\mathrm{o}}$ peak amplitude in SLE phase 1 was faster in layer $1(9.86 \pm 7.42 \mathrm{~s})$ compared with deeper positions $(30.75 \pm 6.74 \mathrm{~s}$ at $300 \mu \mathrm{m} ; 37.47 \pm 11.26 \mathrm{~s}$ at $500 \mu \mathrm{m} ; 32.73 \pm 5.61 \mathrm{~s}$ at $750 \mu \mathrm{m})$. The $\left[\mathrm{K}^{+}\right]_{\mathrm{o}}$ shift at 500 and $750 \mu \mathrm{m}$ depth were comparable and were pooled together. In layers $2-3,\left[\mathrm{~K}^{+}\right]_{\mathrm{o}}$ reached amplitude maxima during phase 3 (Figs. 3, $4 A, B) \cdot\left[\mathrm{K}^{+}\right]_{\mathrm{o}}$ peak amplitudes were not significantly different in layer 1 and layers 2-3 (one-way ANOVA, $p=0.07$; Fig. 4A.C). These findings demonstrated that the $\left[\mathrm{K}^{+}\right]_{\mathrm{o}}$ increase at PC surface is significantly faster compared with $\mathrm{K}^{+}$changes measured in deeper PC layers.

The plot of the correlation between the $\left[\mathrm{K}^{+}\right]_{\mathrm{o}}$ changes and the speed of $\left[\mathrm{K}^{+}\right]_{\mathrm{o}}$ rise (first $\mathrm{K}^{+}$derivative) recorded in layer 1 showed that $\left[\mathrm{K}^{+}\right]_{\mathrm{o}}$ fluctuated cyclically at each PSO around values between 3 and $4 \mathrm{~mm}$ (Fig. 5B). At the transition into SLE (time point $a$ ) the velocity of $\left[\mathrm{K}^{+}\right]_{\mathrm{o}}$ changes slowed down and further increased (bifurcation point $b$ ) at the onset of SLE. A similar plot was observed in nine experiments of 13. The slope of the field potential change occurred, on average, $60 \mathrm{~ms}$ after the onset of the increase in $\left[\mathrm{K}^{+}\right]_{\mathrm{o}}$ rise (time point $b$ in Fig. $5 A, B$ measured as first $\mathrm{K}^{+}$derivative). Note that the maximal acceleration of the $\mathrm{K}^{+}$signal (second $\mathrm{K}^{+}$derivative) preceded the peak amplitude in the field potential. These data demonstrate the following: (1) the transition to SLE consistently initiates at the peak of a PSO cycle (point $a$ ), (2) the transition into SLE is marked by the absence of a $\left[\mathrm{K}^{+}\right]_{\mathrm{o}}$ recovery in the $a-b$ period, and (3) the large potential deflection associated with SLE onset is heralded by a $\left[\mathrm{K}^{+}\right]_{\mathrm{o}}$ increase in layer 1 (point $b$ ). 
A

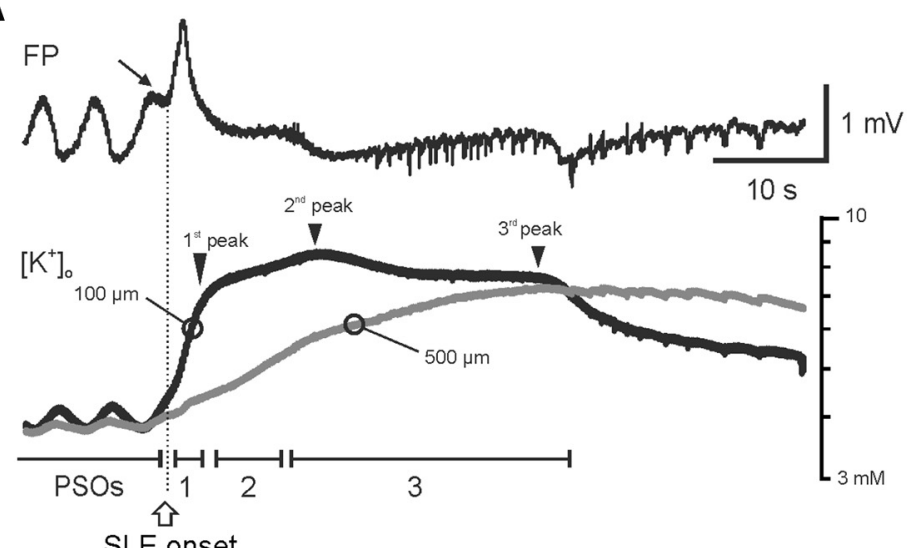

B

time to max peak

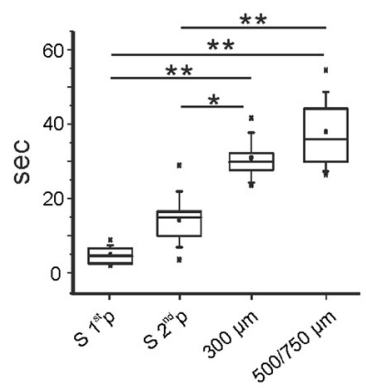

$\mathbf{F}$

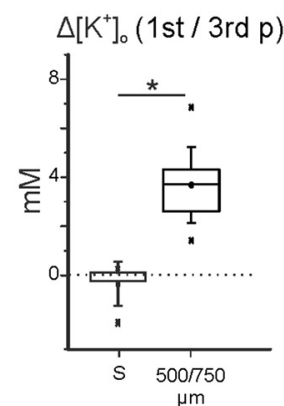

Figure 4. Extracellular potassium changes in superficial and deep PC layers during SLEs. In all experiments, $\left[\mathrm{K}^{+}\right]_{0}$ shifts were recorded in the superficial layers and deep in the cortex $(\geq 300 \mu \mathrm{m})$ with one or two electrodes. $A$, Top trace, Field potential (FP) recorded at $500 \mu \mathrm{m}$ depth showing PSOs and SLE induced by arterial application of $4 \mathrm{AP}(50 \mu \mathrm{m} ; 4 \mathrm{~min})$. The bottom traces show [K $\left.{ }^{+}\right]_{0}$ changes simultaneously recorded at $100 \mu \mathrm{m}$ (black trace, surface) and at $500 \mu \mathrm{m}$ depth (gray trace). Three $\left[\mathrm{K}^{+}\right]_{0}$ peaks are indicated by the arrowheads. The open arrow and dotted line indicate SLE onset. $\boldsymbol{B}$, Box plots of the time to maximal peak of $\left[\mathrm{K}^{+}\right]_{0}$ changes at different $\mathrm{PC}$ depth positions; $n$ values are $7,8,5$, and 8 , respectively from 10 brains. A faster increase of $\left[\mathrm{K}^{+}\right]_{0}$ was recorded at surface $(S)$ compared with deep positions $\left(300,500 / 750 \mu \mathrm{m}\right.$ from pial surface; $F_{(3,24)}=29.12, p=3.61 \mathrm{E}-8$ from one-way ANOVA; $p=1.04 \mathrm{E}-5$ and $q=8.84$ for $S$-first peak vs $300 \mu \mathrm{m} ; p=$ 0.002 and $q=5.76$ for S-second peak vs $300 \mu \mathrm{m} ; p=0.073$ and $q=3.64$ for S-first peak vs S-second peak; $p=0.62$ and $q=1.71$ for $500 / 750$ vs $300 \mu \mathrm{m} ; p=11.4 \mathrm{E}-7$ and $q=11.88$ for $500 / 750$ vs $S$-first peak; $p=1.77 \mathrm{E}-5$ and $q=8.53$ for $500 / 750 \mu \mathrm{m}$ vs $S$-second peak, from post hoc Tukey test). C, Maximal changes of $\left[\mathrm{K}^{+}\right]_{0}$ measured at different depths during SLE. $n$ values are 13,6 , and 9 , respectively from 10 brains. The differences in $\left[\mathrm{K}^{+}\right]_{0}$ were not statistically significant as demonstrated by ANOVA $\left(F_{(2,25)}=3.01, p=0.07\right.$. $p=0.06$ and $q=3.43$ for $300 \mu \mathrm{m}$ vs $S ; p=0.86$ and $q=0.73$ for $500 / 750 \mu \mathrm{m}$ vs $S ; p=0.18$ and $q=2.61$ for $500 / 750$ vs 300 from post hoc Tukey test). $\boldsymbol{D}$, $\left[K^{+}\right]_{0}$ changes measured between onset to the first peak at the surface and at $500 / 750$ $\mu \mathrm{m}$ depth. $n$ values are 13 and 9 , respectively, from 9 brains $\left(t_{(12.67)}=5.58, p=9.84 \mathrm{E}-5\right.$ with two-sample $t$ test; $F=0.02$ and $p=6.65 \mathrm{E}-6$ from Levene's test). $\boldsymbol{E}_{\text {, }}\left[\mathrm{K}^{+}\right]_{0}$ increase between the first and the second peak measured at surface and in deep positions $(500 / 750 \mu \mathrm{m}) . n$ values are 7 and 6 from 7 brains $\left(U=12\right.$ and $p=0.22$ from Mann-Whitney test). $\boldsymbol{F}_{,}\left[K^{+}\right]_{0}$ changes between the first and third peak measured at surface and in deeper position $(500 / 750 \mu \mathrm{m})$. $n$ values are 5 and 9 from 5 brains, respectively $(U=45$ and $p=0.003$ from Mann-Whitney test). Box ranges indicate the 25th and 75th percentile and the whiskers indicate the SD. ${ }^{*} p<0.05{ }^{* *} p<0.001$.

To summarize, the data from these experiments demonstrate that SLEs are initiated by a large $\left[\mathrm{K}^{+}\right]_{\mathrm{o}}$ increase localized in PC layer 1 that occurs at the peak of a PSO mediated by DNQXdependent excitatory activity.

$\left[\mathrm{K}^{+}\right]_{\mathrm{o}}$ propagates to PC deep layers during SLE development $\left[\mathrm{K}^{+}\right]_{\mathrm{o}}$ profiles at surface revealed 2 amplitude peaks with a delay of $4.60 \pm 2.5 \mathrm{~s}$ and $14.14 \pm 7.49 \mathrm{~s}$ from SLE phase 1 peak, respectively ( $n=7$ and 8 ). Both the first and the second $\left[\mathrm{K}^{+}\right]_{\mathrm{o}}$ peaks preceded maxima values in deeper PC positions (third $\left[\mathrm{K}^{+}\right]_{\mathrm{o}}$ peak at $35.69 \pm 9.35 \mathrm{~s}$ at $500 / 750 \mu \mathrm{m}$; Fig. $\left.4 A, B\right)$. These data confirmed that the fast $\left[\mathrm{K}^{+}\right]_{\mathrm{o}}$ increase in superficial PC layers is followed by a second $\left[\mathrm{K}^{+}\right]_{0}$ rise in deeper PC layers. $\left[\mathrm{K}^{+}\right]_{\mathrm{o}}$ shifts occurring at SLE onset were significantly higher in superficial layers $(2.98 \pm 1.68 \mathrm{~mm})$ than at $500 / 750 \mu \mathrm{m}$ depths $(0.34 \pm 0.35 \mathrm{~mm}$; $t$ test, $p=9.84 \mathrm{E}-5$; Fig. $4 D) .\left[\mathrm{K}^{+}\right]_{\mathrm{o}}$ rise between the first and second $\mathrm{K}^{+}$peak (when the latter was present) were $1.06 \pm 0.84 \mathrm{~mm}$ in layer 1 and $2.02 \pm 1.56 \mathrm{~mm}$ in layers $2-3$ (Fig. $4 E$ ). The difference in $\left[\mathrm{K}^{+}\right]_{\mathrm{o}}$ changes between the first and the third peak were $-0.48 \pm 0.92 \mathrm{mM}$ at the surface and $3.67 \pm 1.56 \mathrm{~mm}$ at $500 / 750 \mu \mathrm{m}$ (Fig. $4 F$ ). When only the experi- ments with paired recordings simultaneously performed at surface and $500 \mu \mathrm{m}$ depth were considered, both paired $t$ test and Wilcoxon signed-rank test showed significant $\mathrm{K}^{+}$shift difference between superficial and deep layers in onset/firstpeak (paired $t_{(4)}=3.71, p=$ 0.020 ); first/second peak values were confirmed not to be statistically significant (paired $t_{(3)}=-0.035, p=0.97$ ) and second/third peak values were larger in deep layers compared with superficial layers without a statistical significance (Wilcoxon signed-rank test, $p=0.059)$.

The $\left[\mathrm{K}^{+}\right]_{\mathrm{o}}$ amplitude peak observed in the deeper PC layers during phase 3 (third peak) correlated with prominent spiking at the end of the SLE. Deep-layer $\mathrm{K}^{+}$changes were not coupled with further increase of superficial $\left[\mathrm{K}^{+}\right]_{\mathrm{o}}$ (left SLE in Fig. 3), suggesting that late $\left[\mathrm{K}^{+}\right]_{\mathrm{o}}$ increase in deep layers depends on cell discharge and is not sustained by $\left[\mathrm{K}^{+}\right]_{\mathrm{o}}$ rise in superficial layer 1 . In 3 experiments in which spikes were not observed at the end of a SLE, the superficial first peak $\left[\mathrm{K}^{+}\right]_{\mathrm{o}}$ increase was unchanged, whereas a lower and shorter $\left[\mathrm{K}^{+}\right]_{\mathrm{o}}$ rise was measured in the deeper layers (gray traces in right SLE of Fig. 3).

These findings demonstrate that $\left[\mathrm{K}^{+}\right]_{\mathrm{o}}$ slowly rises in deep PC layers and follows a $\left[\mathrm{K}^{+}\right]_{\mathrm{o}}$ increase of superficial layer 1 and SLEs 

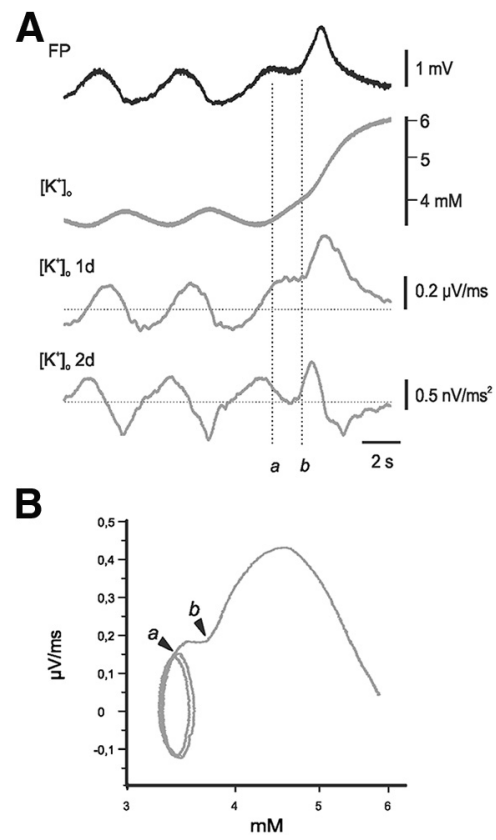

Figure 5. Superficial potassium shifts precede the field potential at SLE onset. A, Representative recording of a transition between PSOS and SLE: the black and gray lines respectively represent the field potential and the $\mathrm{K}^{+}$changes. The third and fourth gray traces from the top are the first time derivative $\left(\left[\mathrm{K}^{+}\right]_{0} 1 \mathrm{~d}\right)$ and the second derivative $\left(\left[\mathrm{K}^{+}\right]_{0} 2 \mathrm{~d}\right)$ of the $\mathrm{K}^{+}$trace that represent, respectively, the velocity and the acceleration of $\mathrm{K}^{+}$shifts. $\boldsymbol{B}$, Plot of the velocity of $\mathrm{K}^{+}$changes (third trace from top in $\boldsymbol{A}$ ) as a function of the $\mathrm{K}^{+}$changes ( $x$-axis). Deflection point $a$ represents the transition from PSOs to SLE. Deflection points $b$ marks the onset of the fast $\mathrm{K}^{+}$increase associated with SLE onset. These time points are marked by the dotted lines in $\boldsymbol{A}$.

onset; these slow changes are partially sustained by the spiking activity observed during SLE phases 2 and 3. The data strongly suggest that $\left[\mathrm{K}^{+}\right]_{\mathrm{o}}$ diffuses from superficial to deep PC layers during 4APinduced SLEs.

\section{Structural features of PC layer 1}

The experiments described above demonstrate that SLEs are initiated by a $\left[\mathrm{K}^{+}\right]_{\mathrm{o}}$ elevation, likely generated by $4 \mathrm{AP}$-driven activity at local synapses in PC layer 1 . SLE progression is associated with diffusion of $\mathrm{K}^{+}$from superficial to deep layers, where neurons can be recruited to generate neuronal firing independent of synchronous synaptic inputs. To contextualize the neurophysiological findings observed at SLE onset in the superficial PC layer, we analyzed the specific structural features of layer 1 .

PC layer 1 is characterized by the virtual absence of neurons, with the exception of sparse GABAergic interneurons (Neville and Haberly, 2004) and is formed by laminarily segregated fiber contingents originating in the olfactory bulbs (LOT fibers forming most superficial layer 1a) and by intrinsic PC corticocortical associative fibers (layer 1b). Both LOT and associative fibers terminate with excitatory synapses on the apical dendrites of principal cells with soma located in layers 2 and 3 that reach out into layer 1 (see also Biella and de Curtis, 1995 and Neville and Haberly, 2004). Studies on guinea pig and opossum demonstrated that the axon terminals of LOT and intra-PC associative fibers are not myelinated (Haberly and Feig, 1983; Gracey and Scholfield, 1990). As shown in Figure 6A, in the guinea pig brain, the myelinspecific Black-Gold II staining marked the subcortical white matter (Fig. 6A, arrows in the upper left panel) and the LOT (Fig. 6A, double arrows), but did not stain layer 1 of the PC (Fig. $6 A$, right panel). Sparse myelin staining was observed in the neuropile of deep PC layers (Fig. 6A, white arrows). The absence of myelin around axons was verified by electron microscopy on layer 1 ultrathin sections (Fig. 6B) and was quantified by counting myelinated ( $\mathrm{mf}$ ) and unmyelinated (umf) axon fibers in sublayers 1a and $1 \mathrm{~b}$, as shown in Figure $6 C$. These findings confirmed that the PC superficial layer 1 contains a dense arrangement of unmyelinated axons. This feature could be relevant for the generation of SLEs in the 4AP model (see Discussion).

\section{Human seizure patterns with 4AP-SLE features}

We analyzed seizure pattern features in a cohort of patients candidate to epilepsy surgery explored with intracranial depth electrodes according a stereotactic procedure (see Materials and Methods). In a population of 100 patients consecutively explored in the last 5 years at the Claudio Munari Epilepsy Surgery Center, two prevalent stereo-EEG seizure patterns were observed (Gnatkovsky et al., 2016): (1) long seizures ( $>40 \mathrm{~s})$ characterized by a low-voltage fast activity onset superimposed to a slow wave that progressed into irregular spiking and terminated with a periodic bursting was observed in mesial temporal and temporal cortical areas (Fig. $7 A ; \sim 50 \%$ of cases); and (2) brief seizures (7-30 s) that initiated and ended with an abrupt, large-amplitude plateau potential superimposed by fast activity of small amplitude (Figs. $7 B, 8 ; \sim 35 \%$ of cases) were commonly observed in the frontal lobe. This pattern was not associated with a specific underlying pathology (Gnatkovsky et al., 2016).

The latter seizure pattern resembled the 4AP-induced SLEs recorded in the $\mathrm{PC}$ of the isolated guinea pig brain (Fig. 8). The slow potentials typical of this seizure type were masked when the standard setting of high-pass filters (HPFs) was used (left column in Fig. $8 A$, seizure 1 with $\mathrm{HPF}$ at $0.5 \mathrm{~Hz}$ ) and became evident when intracranial recordings were unfiltered for low frequencies (right column in Fig. 8A, seizure 1; HPF at $0.016 \mathrm{~Hz}$ ). As for PC, seizures progressed with fast activity in the beta/gamma range and continued with the appearance of recruiting spiking activity that abruptly terminated with a large-amplitude slow potential (asterisks in Fig. 8). Slow oscillatory sequences similar to PSOs could be observed just ahead of this type of seizures (Fig. $8 \mathrm{~A}$, seizure 2, $8 B$, patient 2 ).

\section{Discussion}

The PC in the isolated guinea pig brain does not generate ictal discharges after diverse pharmacological manipulations such as perfusion of bicuculline, kainic acid, and pilocarpine (de Curtis et al., 2016). Moreover, the ictal pattern observed in the PC (Uva et al., 2013) during 4AP perfusion differs from SLEs usually observed in limbic regions in animal models in vivo (Lothman et al., 1991; Bragin et al., 1999c), in vitro (Avoli et al., 2002; Uva et al., 2005; Boido et al., 2014), and in humans (Bragin et al., 1999a, 1999b; Bartolomei et al., 2001), which are characterized by fast activity preceded by large amplitude spikes and followed by recruiting tonic spiking and bursting phases (de Curtis and Gnatkovsky, 2009). These findings demonstrate that the unusual SLE pattern generated by $4 \mathrm{AP}$ in the $\mathrm{PC}$ is specific of this region and suggest that the underlying network mechanisms are different from those reported for limbic and temporal lobe seizures.

On the basis of neurophysiological experiments, we demonstrate that 4AP-induced SLEs in the PC: (1) originate in the plexiform layer 1 lacking principal neurons soma at the peak of a glutamate receptor-dependent PSO, (2) initiate with a very large, surface-negative slow potential associated to a fast $\left[\mathrm{K}^{+}\right]_{\mathrm{o}}$ increase, (3) progress with the suppression of synchronous synaptic activity and with sparse 
A
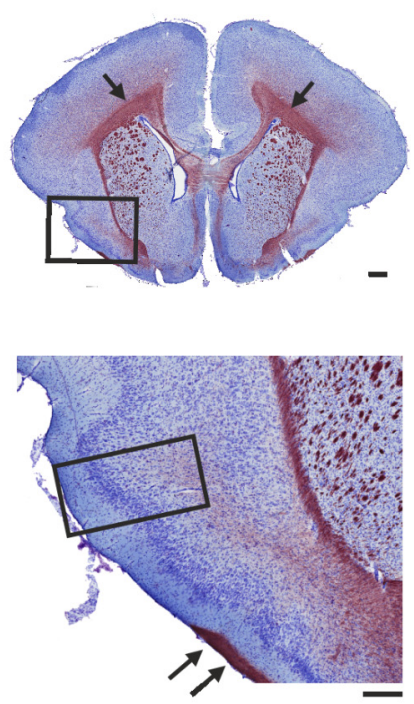

B

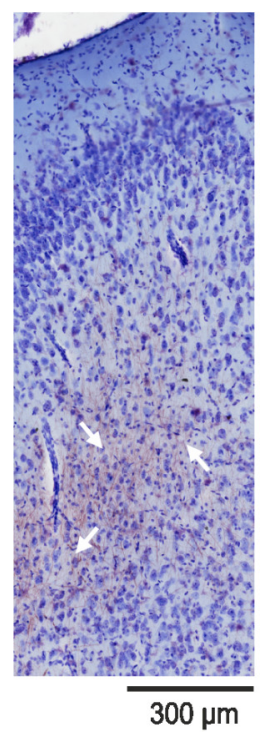

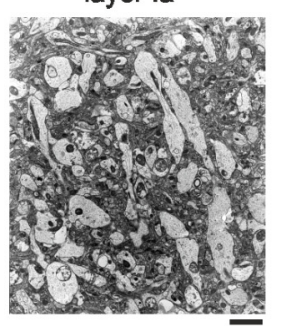

C
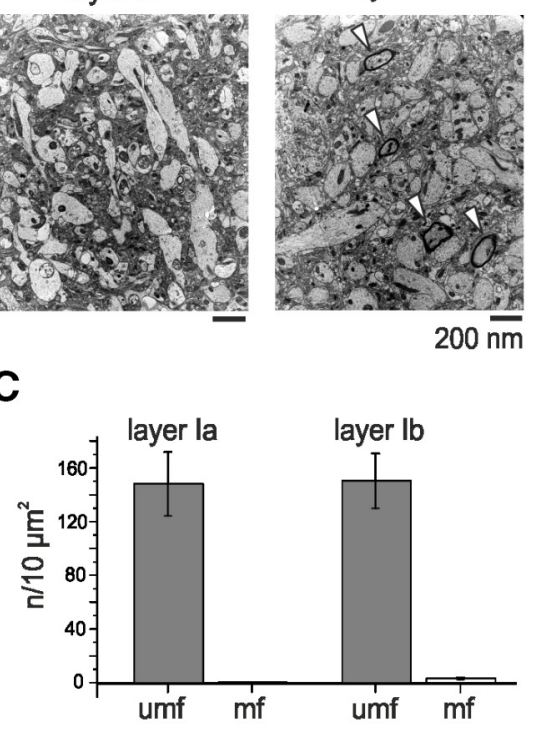

Figure 6. Microscopic features of superficial layer 1 of the guinea pig PC. $A$, Coronal sections of the PC stained for the myelin marker Black-Gold II at different magnifications. Myelin is clearly illustrated by the red staining of subcortical fibers (arrows), of LOT (double arrows), and in the neuropil of deep PC layers (white arrows). Sections are counterstained with thionine. B, Electronic microscope photographs of layer $1 \mathrm{a}$ and $\mathrm{1b}$. The white arrowheads mark sporadic myelinated fibers in layer $1 \mathrm{~b}$. C, Quantification of unmyelinated (umf) and myelinated fibers ( $\mathrm{mf}$ ) in the $\mathrm{PC}$ superficial layers la and lb.

A
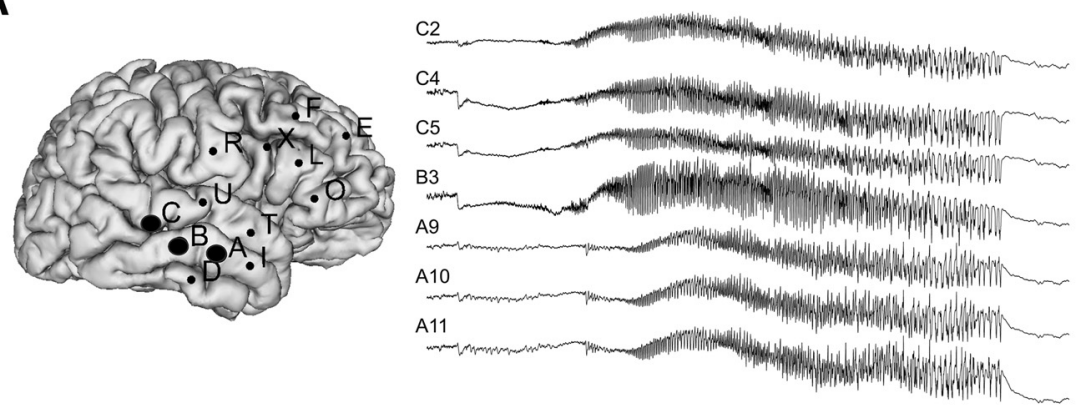

\section{B}
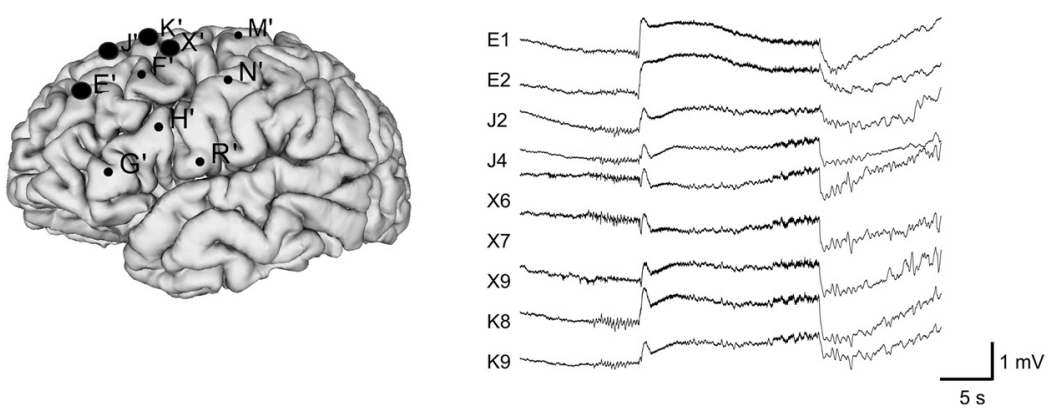

Figure 7. Seizure patterns recorded with intracerebral electrodes during presurgical monitoring in patients with drug-resistant focal epilepsy. Two main types of seizures recorded in patients submitted to intracranial EEG monitoring for epilepsy surgery. Seizures in the temporal lobe and from frontal neocortex are shown in $\boldsymbol{A}$ and $\boldsymbol{B}$, respectively. $3 \mathrm{D}$ reconstruction of the position of the recording electrodes based on magnetic resonance imaging is illustrated.

neuronal firing of layer 2-3 neurons (Uva et al., 2013), (4) propagate to deep layers through a $\left[\mathrm{K}^{+}\right]_{\mathrm{o}}$ wave reinforced by the generation of local neuronal firing, and (5) terminate abruptly with a return of $\left[\mathrm{K}^{+}\right]_{\mathrm{o}}$ to pre-SLE values. These elements are discussed here in the framework of the structural organization of the PC and a hypothesis on the possible network events responsible for this novel seizure type is formulated (Fig. 9).

Field potential laminar profiles performed with 16-channel silicon probes demonstrated that PSOs and SLEs are generated within the most superficial 200 $\mu \mathrm{m}$ that correspond to PC layer 1. Both depend on the preservation of connectivity within superficial layers because they are observed in tangential slices (Galvan et al., 1982), but could not be reproduced in coronal PC slices that retain a limited intrinsic PC network (see also Panuccio et al., 2012 in rat coronal PC slices). SLE onset is associated with increased $\left[\mathrm{K}^{+}\right]_{\mathrm{o}}$ in the superficial layer 1 of the PC. Except for sparse bipolar interneurons, layer 1 is composed of a dense net of spatially segregated unmyelinated axon fibers that originate from olfactory bulb neurons (layer 1a) and by the intra-PC associative network in layer $1 \mathrm{~b}$ (Neville and Haberly, 2004). These two fiber contingents form excitatory synaptic contacts with layer 2 and 3 pyramidal cell apical dendrites reaching out toward the pial surface $(\mathrm{Nev}$ ille and Haberly, 2004). The large and abrupt $\left[\mathrm{K}^{+}\right]_{0}$ increases observed at the onset of a 4AP-mediated SLE (and PSOs) can be generated exclusively by the excitatory glutamate receptor-mediated network activity generated in layer 1 (Carriero et al., 2010). Conversely, the coperfusion of $4 \mathrm{AP}$ and bicuculline determined a change in the epileptiform pattern and did not abolish the large potential at SLE onset, suggesting a contribution of GABA in modulating the epileptiform activity and ex- 
A patient 1

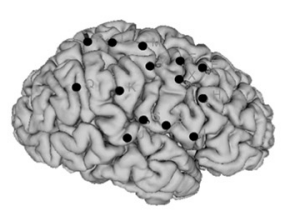

seizure 1
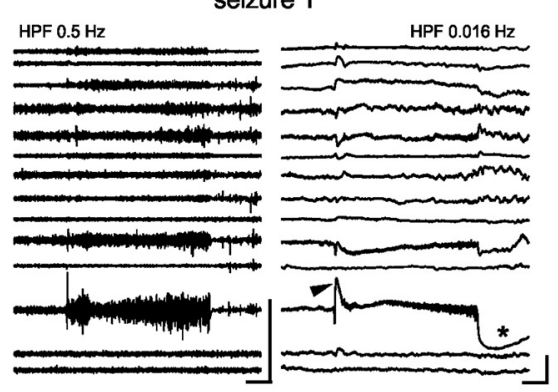
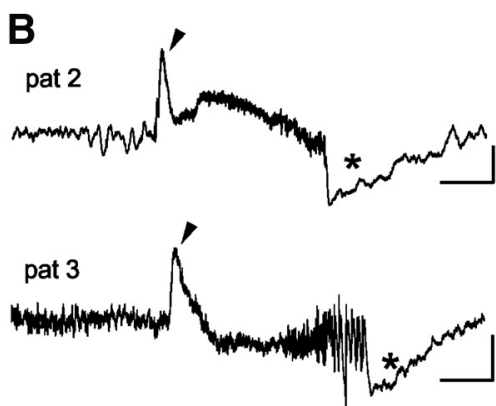

seizure 2

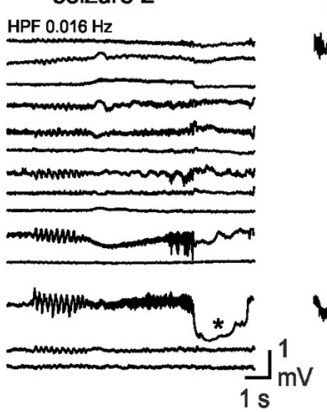

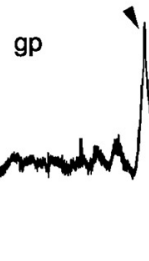

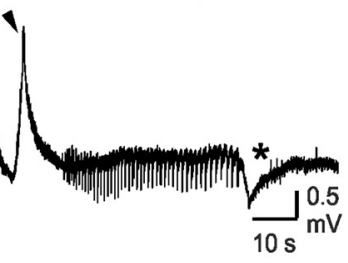

Figure 8. Intracranial human seizure pattern similar to experimental PC SLE. A, Scheme of the stereo-EEG implant of intracerebral electrodes for one of the patients included in the study (patient 1) submitted to intracranial EEG monitoring for epilepsy surgery. 3D reconstruction of the position of the recording electrodes is based on magnetic resonance imaging. A coronal MR section with the position of two intracerebral electrodes is shown on the right. The EEG traces recorded from patient 1 during two different seizures are illustrated below. Traces recorded during seizure 1 are shown with HPFs at $0.5 \mathrm{~Hz}$ (seizure 1, left) and at $0.016 \mathrm{~Hz}$ (seizure 1, right). Slow potentials at the onset (arrowhead) and at the end (asterisk) of the seizure were revealed in the epileptogenic zone when the HPF was set at $0.016 \mathrm{~Hz}$. Another seizure (seizure 2; rightmost traces) recorded from the same patient showed slow oscillations at the onset. $\boldsymbol{B}$, Unfiltered, isolated traces obtained during seizures recorded with intracerebral electrodes in two different patients (patients 2 and 3). Slow potentials at the onset (arrowheads) and at the end (asterisks) of the seizures are illustrated. At the bottom, a PC SLE recorded in the isolated guinea pig brain is shown for comparison.
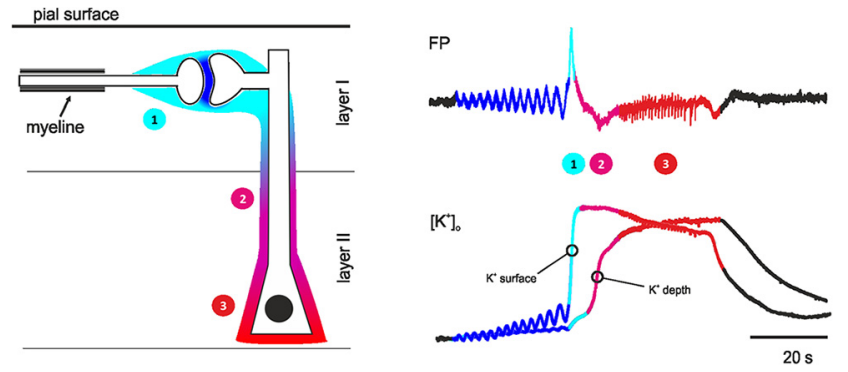

Figure 9. Pathogenic model of $4 A P$-induced SLEs in PC. Schematic representation of PC layers I and II (left): fibers lose their myelin sheath as they enter and distribute into layer 1. The diffusion of $\mathrm{K}^{+}$ions is represented by the colored shaded areas that correspond to different phases of the PSOs-SLE complex illustrated on the right with field potential (FP) and $\left[\mathrm{K}^{+}\right]_{0}$ traces recorded in both superficial and deep PC layers. Network activity occurring during PSOs releases $\mathrm{K}^{+}$in the synaptic cleft (blue shading). We propose that $\mathrm{K}^{+}$is not properly buffered at the onset of SLE and accumulates in layer 1 (phase 1; light blue shading and traces), where it depolarizes unmyelinated fibers and postsynaptic terminals and blocks synaptic transmission. The accumulated $\mathrm{K}^{+}$slowly diffuses to layer 2 (and 3 ) and depolarizes neurons during phase 2 (purple shading and traces). The progressive recruitment of neuronal activity induces the delayed increase of extracellular $\mathrm{K}^{+}$(transition to phase 3; red shading and traces) that sustains SLE progression. SLEs end with abrupt drop in superficial layer $\mathrm{K}^{+}$that correlates with a deep-negative potential shift.

cluding a role of GABA-mediated activity in the generation of PC SLEs (Uva et al., 2014).

The elevated expression of the two main subtypes of dendritic $4 \mathrm{AP}$-sensitive $\mathrm{K}^{+}$channels, $\mathrm{Kv} 4.2$ and $\mathrm{Kv} 4.3$, in PC layer 1 (Johenning et al., 2009) supports a specific effect of 4AP in this layer. These observations suggest that the onset of a SLE and the preceding PSOs are sustained by enhanced excitatory activity at layer $1 \mathrm{a}$ and $1 \mathrm{~b}$ terminals, possibly supported by the slowing of presynaptic axon terminal repolarization mediated by the $\mathrm{K}^{+}$channel blocker 4AP, as reported in PC slices (Galvan et al., 1984). The slowing of spike repolarization prolongs action potential duration in axon terminals and promotes a larger release of neurotransmitter and a stronger postsynaptic activation (Galvan et al., 1984). The building up of network activity and the consequent $\mathrm{K}^{+}$release during pre-SLE PSOs could be mediated by this mechanism.

It has been proposed that myelin conveys the $\mathrm{K}^{+}$released during presynaptic activity to the astrocyte syncytium, where it is buffered by glial-specific mechanisms (Rash, 2010). This protective mechanism is not present in unmyelinated fibers. Although $\mathrm{K}^{+}$efflux in myelinated axons occurs in a protected compartment beneath the myelin, $\mathrm{K}^{+}$released by unmyelinated fibers is free to diffuse in the periaxonal space. Therefore, unmyelinated fibers that form LOT axon terminals and intra-PC associative fibers contribute to enhance $\left[\mathrm{K}^{+}\right]_{\mathrm{o}}$; in addition, unmyelinated fibers are more susceptible to changes in $\mathrm{K}^{+}$than myelinated fibers. Increased $\left[\mathrm{K}^{+}\right]_{\mathrm{o}}$ reduces transmembrane potassium flux, depolarizes unmyelinated axons (Scholfield, 1990), and makes them more excitable and thus more prone to further release $\mathrm{K}^{+}$; when fiber depolarization is excessive due to $\left[\mathrm{K}^{+}\right]_{\mathrm{o}}$ accumulation, impairment of axon conductivity may occur (Timofeev and Steriade, 2004; Seigneur and Timofeev, 2011; Bay and Butt, 2012). Therefore, the sensitivity of presynaptic unmyelinated PC fibers to enhanced $\mathrm{K}^{+}$may account for the blockade of LOTevoked responses observed at the onset and during the progression of SLE in our experiments. It was no just LOT-induced neuronal firing that was blocked during phase 1-2 SLE; the field response to LOT stimulation localized in superficial layers (Neville and Haberly, 2004) was abolished, corroborating the conclusion that presynaptic activity in superficial layers is impaired during SLE (but not at its onset). The possibility that postsynaptic distal dendrite/spine depolarization of layer II neurons could contribute to the disappearance of LOT-evoked response could also be considered. Synchronous synaptic transmission blockade is not common during seizures and can be recognized as a peculiar phenomenon occurring in the SLE pattern described here. We observed, indeed, that stimulus-evoked responses are preserved in limbic cortices during bicuculline and 4AP-induced seizures (D. Boido and L. Uva, unpublished observations). Interestingly, the enhanced 
$\left[\mathrm{K}^{+}\right]_{\mathrm{o}}$-mediated depolarization of unmyelinated axons further enhances extracellular $\mathrm{K}^{+}$since unmyelinated fibers are expected to release more $\mathrm{K}^{+}$than myelinated fibers during axonal activation.

LOT synaptic terminals on the distal apical dendrites of deep layer neurons located in PC superficial layer 1 are outlined by astrocytic envelopes (Haberly and Feig, 1983; L. Uva and S. Saccucci, unpublished observations). Astrocyte enfoldings around excitatory terminals are expected to limit the diffusion of neurotransmitters and $\mathrm{K}^{+}$in the molecular layer 1 densely packed with unmyelinated fibers and synapses. These synaptic specializations could fail their insulating function when presynaptic activity is enhanced by 4AP application. Moreover, direct depolarization of astrocytes by 4AP (Bordey and Sontheimer, 1999; Grimaldi et al., 2001) could reduce $\mathrm{K}^{+}$uptake from the extracellular space and further impairs glial buffering function that depends on the polarization of astrocyte membrane potential. The reduced $\mathrm{K}^{+}$buffer action mediated by the direct effect of $4 \mathrm{AP}$ on glial cells will further enhance $\left[\mathrm{K}^{+}\right]_{\mathrm{o}}$.

Simultaneous recording of $\left[\mathrm{K}^{+}\right]_{\mathrm{o}}$ at different PC depths strongly suggests that $\left[\mathrm{K}^{+}\right]_{\mathrm{o}}$ passively diffuses from superficial layer 1 to deeper layers. High $\mathrm{K}^{+}$depolarizes layer 2 cells by changing the equilibrium potential of different transmembrane ions, and promotes neuronal firing at the beginning of the phase 2 (Traynelis and Dingledine, 1988; Bazhenov et al., 2004). Neuronal firing in layer 2 neurons during SLE phase 2-3 is likely to be responsible for the late increase in $\left[\mathrm{K}^{+}\right]_{\mathrm{o}}$ observed in deep layers. A previous study demonstrated that neuronal firing in layer 2 neurons during both PSOs and SLEs is occasional and not synchronous (Uva et al., 2013), suggesting that layer 2 pyramidal cells are not likely to contribute to SLE onset. The concept that SLE is not initiated by synchronous activity of PC layer II neurons is further supported by the evidence that the fast $\left[\mathrm{K}^{+}\right]_{\mathrm{o}}$ surge at SLE onset precedes neuronal discharges of layer 2-3 neurons that resumes during SLE phase 2-3.

Taking into consideration the micro-anatomical features of the PC and the above-discussed implications, we propose the following scheme to explain the mechanisms of ictogenesis induced by $4 \mathrm{AP}$ in the PC (Fig. 9). During PSOs, excitatory transmitter release at layer 1 synapses is enhanced due to 4AP-induced $\mathrm{K}_{\mathrm{A}}$-channel blockade; PSOs generate $\mathrm{K}^{+}$changes (dark blue shading) that are physiologically buffered by perisynaptic astrocytic specializations. When $\left[\mathrm{K}^{+}\right]_{\mathrm{o}}$ increases beyond the threshold of the buffering capability of astrocyte envelopes, $\mathrm{K}^{+}$leak of the synaptic specialization further depolarizes unmyelinated axon fibers (further reinforcing $\mathrm{K}^{+}$accumulation) and blocks presynaptic transmission; this corresponds to the $\mathrm{K}^{+}$increase associated with depth-positive extracellular large potential during SLE phase 1 (light blue shading). Extracellular $\mathrm{K}^{+}$slowly diffuses to deeper layers and depolarizes postsynaptic neurons in layer 2-3 (light purple in phase 2); neuronal firing recruited during phase 2-3 further increases $\left[\mathrm{K}^{+}\right]_{\mathrm{o}}$ in deep layers (red shading). SLE ends with an abrupt recovery of $\left[\mathrm{K}^{+}\right]_{\mathrm{o}}$ in superficial layers that correlates to a deep-negative slow potential.

In conclusion, this study describes for the first time a novel seizure pattern generated in superficial layers, which is associated with $\mathrm{K}^{+}$released by unmyelinated axons/axon terminal hyperactivity and does not require the participation of synchronous synaptic transmission for its progression. The hypothesized sequence of events based on the experiments on the isolated guinea pig brains stands as a novel mechanism of ictogenesis. The relevance of these findings for understanding human epilepsy could be hypothesized by the observation that the novel SLE pattern mimics seizure activity patterns recorded with intracerebral elec- trodes mainly in frontal cortical areas of patients with focal drugresistant epilepsy. The possibility that deranged tissue function engaging unmyelinated fibers might play a role in the generation of brief seizure events in humans is supported by the observation that unmyelinated fibers are pathologically augmented in the epileptogenic focal cortical dysplasias (Shepherd et al., 2013; Zucca et al., 2016) and in the cortical tissue of temporal lobe epilepsies with and without associated dysplasia (Garbelli et al., 2012). Although correlative, this evidence supports the notion that potassium homeostasis and unmyelinated fibers represent a potential vehicle for focal ictogenesis.

\section{References}

Avoli M, D’Antuono M, Louvel J, Köhling R, Biagini G, Pumain R, D’Arcangelo G, Tancredi V (2002) Network and pharmacological mechanisms leading to epileptiform synchronization in the limbic system in vitro. Prog Neurobiol 68:167207. CrossRef Medline

Bartolomei F, Wendling F, Bellanger JJ, Régis J, Chauvel P (2001) Neural networks involving the medial temporal structures in temporal lobe epilepsy. Clin Neurophysiol 112:1746-1760. CrossRef Medline

Bay V, Butt AM (2012) Relationship between glial potassium regulation and axon excitability: a role for glial Kir4.1 channels. Glia 60:651-660. CrossRef Medline

Bazhenov M, Timofeev I, Steriade M, Sejnowski TJ (2004) Potassium model for slow $(2-3 \mathrm{~Hz})$ in vivo neocortical paroxysmal oscillations. J Neurophysiol 92:1116-1132. CrossRef Medline

Biella G, de Curtis M (1995) Associative synaptic potentials in the piriform cortex of the isolated guinea pig brain in vitro. Eur J Neurosci 7:54-64. CrossRef Medline

Boido D, Jesuthasan N, de Curtis M, Uva L (2014) Network dynamics during the progression of seizure-like events in the hippocampal-parahippocampal regions. Cereb Cortex 24:163-173. CrossRef Medline

Bordey A, Sontheimer H (1999) Differential inhibition of glial $\mathrm{K}(+)$ currents by 4-AP. J Neurophysiol 82:3476-3487. Medline

Bragin A, Engel J Jr, Wilson CL, Fried I, Buzsáki G (1999a) High-frequency oscillations in human brain. Hippocampus 9:137-142. Medline

Bragin A, Engel J Jr, Wilson CL, Fried I, Mathern GW (1999b) Hippocampal and entorhinal cortex high-frequency oscillations $(100-500 \mathrm{~Hz})$ in human epileptic brain and in kainic acid-treated rats with chronic seizures. Epilepsia 40:127-137. CrossRef Medline

Bragin A, Engel J Jr, Wilson CL, Vizentin E, Mathern GW (1999c) Electrophysiologic analysis of a chronic seizure model after unilateral hippocampal KA injection. Epilepsia 40:1210-1221. CrossRef Medline

Cardinale F, Cossu M, Castana L, Casaceli G, Schiariti MP, Miserocchi A, Fuschillo D, Moscato A, Caborni C, Arnulfo G, Lo Russo G (2013) Stereoelectroencephalography: surgical methodology, safety, and stereotactic application accuracy in 500 procedures. Neurosurgery 72:353-366. CrossRef Medline

Carriero G, Uva L, Gnatkovsky V, Avoli M, de Curtis M (2010) Independent epileptiform discharge patterns in the olfactory and limbic areas of the in vitro isolated Guinea pig brain during 4 -aminopyridine treatment. J Neurophysiol 103:2728-2736. CrossRef Medline

Centeno M, Vollmar C, Stretton J, Symms MR, Thompson PJ, Richardson MP, O’Muircheartaigh J, Duncan JS, Koepp MJ (2014) Structural changes in the temporal lobe and piriform cortex in frontal lobe epilepsy. Epilepsy Res 108:978-981. CrossRef Medline

Cossu M, Cardinale F, Castana L, Citterio A, Francione S, Tassi L, Benabid AL, Lo Russo G (2005) Stereoelectroencephalography in the presurgical evaluation of focal epilepsy: a retrospective analysis of 215 procedures. Neurosurgery 57:706-718. CrossRef Medline

de Curtis M, Gnatkovsky V (2009) Reevaluating the mechanisms of focal ictogenesis: the role of low-voltage fast activity. Epilepsia 50:2514-2525. CrossRef Medline

de Curtis M, Paré D, Llinás RR (1991) The electrophysiology of the olfactory-hippocampal circuit in the isolated and perfused adult mammalian brain in vitro. Hippocampus 1:341-354. CrossRef Medline

de Curtis M, Biella G, Forti M, Panzica F (1994) Multifocal spontaneous epileptic activity induced by restricted bicuculline ejection in the piriform cortex of the isolated guinea pig brain. J Neurophysiol 71:2463-2476. Medline

de Curtis M, Biella G, Buccellati C, Folco G (1998) Simultaneous investiga- 
tion of the neuronal and vascular compartments in the guinea pig brain isolated in vitro. Brain Res Brain Res Protoc 3:221-228. CrossRef Medline

de Curtis M, Librizzi L, Uva L (2016) The in vitro isolated whole guinea pig brain as a model to study epileptiform activity patterns. J Neurosci Methods 260:83-90. CrossRef Medline

Demir R, Haberly LB, Jackson MB (1999) Sustained and accelerating activity at two discrete sites generate epileptiform discharges in slices of piriform cortex. J Neurosci 19:1294-1306. Medline

Demir R, Haberly LB, Jackson MB (2001) Epileptiform discharges with invivo-like features in slices of rat piriform cortex with longitudinal association fibers. J Neurophysiol 86:2445-2460. Medline

Federico P, MacVicar BA (1996) Imaging the induction and spread of seizure activity in the isolated brain of the guinea pig: the roles of GABA and glutamate receptors. J Neurophysiol 76:3471-3492. Medline

Galvan M, Grafe P, ten Bruggencate G (1982) Convulsant actions of 4 -aminopyridine on the guinea pig olfactory cortex slice. Brain Res 241: 75-86. CrossRef Medline

Galvan M, Franz P, Vogel-Wiens C (1984) Actions of potassium channel blockers on guinea pig lateral olfactory tract axons. Naunyn Schmiedebergs Arch Pharmacol 325:8-11. CrossRef Medline

Garbelli R, Milesi G, Medici V, Villani F, Didato G, Deleo F, D’Incerti L, Morbin M, Mazzoleni G, Giovagnoli AR, Parente A, Zucca I, Mastropietro A, Spreafico R (2012) Blurring in patients with temporal lobe epilepsy: clinical, high-field imaging and ultrastructural study. Brain 135: 2337-2349. CrossRef Medline

Gnatkovsky V, Francione S, Cardinale F, Mai R, Tassi L, Lo Russo G, de Curtis M (2011) Identification of reproducible ictal patterns based on quantified frequency analysis of intracranial EEG signals, Epilepsia 52:477-488. CrossRef

Gnatkovsky V, de Curtis M, Pastori C, Cardinale F, Lo Russo G, Mai R, Nobili L, Sartori I, Tassi L, Francione S (2014) Biomarkers of epileptogenic zone defined by quantified stereo-EEG analysis. Epilepsia 55:296-305. CrossRef Medline

Gnatkovsky V, Nucci C, Francione S, Sartori I, de Curtis M (2016) What different intracranial EEG seizure patterns can tell us about ictogenic mechanisms. Epilepsia 57(Suppl. 2):10.

Gracey A, Scholfield CN (1990) Studies on unmyelinated axons and varicosities in the olfactory cortex. Exp Brain Res 80:436-440. Medline

Grimaldi M, Atzori M, Ray P, Alkon DL (2001) Mobilization of calcium from intracellular stores, potentiation of neurotransmitter-induced calcium transients, and capacitative calcium entry by 4 -aminopyridine. J Neurosci 21:3135-3143. Medline

Haberly LB, Feig SL (1983) Structure of the piriform cortex of the opossum. II. Fine structure of cell bodies and neuropil. J Comp Neurol 216:69-88. CrossRef Medline

Hoffman WH, Haberly LB (1993) Role of synaptic excitation in the generation of bursting-induced epileptiform potentials in the endopiriform nucleus and piriform cortex. J Neurophysiol 70:2550-2561. Medline

Hoffman WH, Haberly LB (1996) Kindling-induced epileptiform potentials in piriform cortex slices originate in the underlying endopiriform nucleus. J Neurophysiol 76:1430-1438. Medline

Johenning FW, Beed PS, Trimbuch T, Bendels MH, Winterer J, Schmitz D (2009) Dendritic compartment and neuronal output mode determine pathway-specific long-term potentiation in the piriform cortex. J Neurosci 29:13649-13661. CrossRef Medline

Laufs H, Richardson MP, Salek-Haddadi A, Vollmar C, Duncan JS, Gale K, Lemieux L, Löscher W, Koepp MJ (2011) Converging PET and fMRI evidence for a common area involved in human focal epilepsies. Neurology 77:904-910. CrossRef Medline

Lee SA, Spencer DD, Spencer SS (2000) Intracranial EEG seizure-onset patterns in neocortical epilepsy. Epilepsia 41:297-307. CrossRef Medline

Librizzi L, de Curtis M (2003) Epileptiform ictal discharges are prevented by periodic interictal spiking in the olfactory cortex. Ann Neurol 53:382389. CrossRef Medline

Librizzi L, Janigro D, De Biasi S, de Curtis M (2001) Blood brain barrier preservation in the in vitro isolated guinea pig brain preparation. J Neurosci Res 66:289-297. CrossRef Medline

Löscher W, Ebert U (1996) The role of the piriform cortex in kindling. Prog Neurobiol 50:427-481. CrossRef Medline
Lothman EW, Bertram EH 3rd, Stringer JL (1991) Functional anatomy of hippocampal seizures. Prog Neurobiol 37:1-82. CrossRef Medline

Mühlethaler M, de Curtis M, Walton K, Llinás R (1993) The isolated and perfused brain of the guinea pig in vitro. Eur J Neurosci 5:915-926. CrossRef Medline

Munari C, Hoffmann D, Francione S, Kahane P, Tassi L, Lo Russo G, Benabid AL (1994) Stereo-electroencephalography methodology: advantages and limits. Acta Neurol Scand Suppl 152:56-67, discussion 68-69. Medline

Neville KR, Haberly L (2004) Olfactory cortex. In: The synaptic organization of the brain, Ed 5 (Shepherd GM, ed), pp 415-454. New York: OUP.

Ogren JA, Bragin A, Wilson CL, Hoftman GD, Lin JJ, Dutton RA, Fields TA, Toga AW, Thompson PM, Engel JJr, Staba RJ (2009) Three-dimensional hippocampal atrophy maps distinguish two common temporal lobe seizure-onset patterns. Epilepsia 50:1361-1370. CrossRef Medline

Panuccio G, Sanchez G, Lévesque M, Salami P, de Curtis M, Avoli M (2012) On the ictogenic properties of the piriform cortex in vitro. Epilepsia 53: 459-468. CrossRef Medline

Perucca P, Dubeau F, Gotman J (2014) Intracranial electroencephalographic seizure-onset patterns: effect of underlying pathology. Brain 137: 183-196. CrossRef Medline

Piredda S, Gale K (1985) A crucial epileptogenic site in the deep prepiriform cortex. Nature 317:623-625. CrossRef Medline

Rash JE (2010) Molecular disruptions of the panglial syncytium block potassium siphoning and axonal saltatory conduction: pertinence to neuromyelitis optica and other demyelinating diseases of the central nervous system. Neuroscience 168:982-1008. CrossRef Medline

Scholfield CN (1990) Properties of K-currents in unmyelinated presynaptic axons of brain revealed revealed by extracellular polarisation. Brain Res 507:121-128. CrossRef Medline

Seigneur J, Timofeev I (2011) Synaptic impairment induced by paroxysmal ionic conditions in neocortex. Epilepsia 52:132-139. CrossRef Medline

Shepherd C, Liu J, Goc J, Martinian L, Jacques TS, Sisodiya SM, Thom M (2013) A quantitative study of white matter hypomyelination and oligodendroglial maturation in focal cortical dysplasia type II. Epilepsia 54: 898-908. CrossRef Medline

Singh S, Sandy S, Wiebe S (2015) Ictal onset on intracranial EEG: do we know it when we see it? State of the evidence. Epilepsia 56:1629-1638. CrossRef Medline

Talairach J, Bancaud J, Szikla G, Bonis A, Geier S, Vedrenne C (1974) New approach to the neurosurgery of epilepsy. Stereotaxic methodology and therapeutic results. 1. Introduction and history. Neurochirurgie 20:1240. Medline

Tassi L, Colombo N, Garbelli R, Francione S, Lo Russo G, Mai R, Cardinale F, Cossu M, Ferrario A, Galli C, Bramerio M, Citterio A, Spreafico R (2002) Focal cortical dysplasia: neuropathological subtypes, EEG, neuroimaging and surgical outcome. Brain 125:1719-1732. CrossRef Medline

Timofeev I, Steriade M (2004) Neocortical seizures: initiation, development and cessation. Neuroscience 123:299-336. CrossRef Medline

Traynelis SF, Dingledine R (1988) Potassium-induced spontaneous electrographic seizures in the rat hippocampal slice. J Neurophysiol 59:259-276. Medline

Uva L, Librizzi L, Wendling F, de Curtis M (2005) Propagation dynamics of epileptiform activity acutely induced by bicuculline in the hippocampalparahippocampal region of the isolated guinea pig brain. Epilepsia 46: 1914-1925. CrossRef Medline

Uva L, Trombin F, Carriero G, Avoli M, de Curtis M (2013) Seizure-like discharges induced by 4 -aminopyridine in the olfactory system of the in vitro isolated guinea pig brain. Epilepsia 54:605-615 . CrossRef Medline

Uva L, Trombin F, Librizzi L, de Curtis M (2014) Epileptiform discharges induced by 4-aminopyridine in piriform cortex of the isolated guinea pig brain: analysis of the mechanisms. FENS Forum Abstr FENS-0578.

Uva L, Breschi GL, Gnatkovsky V, Taverna S, de Curtis M (2015) Synchronous inhibitory potentials precede seizure-like events in acute models of focal limbic seizures. J Neurosci 35:3048-3055. CrossRef Medline

Zucca I, Milesi G, Medici V, Tassi L, Didato G, Cardinale F, Tringali G, Colombo N, Bramerio M, D'Incerti L, Freri E, Morbin M, Fugnanesi V, Figini M, Spreafico R, Garbelli R (2016) Type II focal cortical dysplasia: Ex vivo $7 \mathrm{~T}$ magnetic resonance imaging abnormalities and histopathological comparisons. Ann Neurol 79:42-58. CrossRef Medline 